\title{
Rio de Janeiro: trajetória institucional e especificidades do marco de poder
}

\author{
Mauro Osorio ${ }^{2}$ \\ Henrique Rabelo Sá Rego ${ }^{3}$ \\ Maria Helena Versiani ${ }^{4}$
}

\section{RESUMO}

A trajetória econômica, política e social da cidade e do estado do Rio de Janeiro é analisada neste artigo, tendo em vista a institucionalidade formal (leis) e informal (hábitos e cultura) que marcou a história da região. São discutidos os impactos dessa institucionalidade para a constituição do marco de poder dominante no Rio de Janeiro, bem como problematizados os desafios existentes para a superação, no século XXI, do longo processo de decadência econômica vivenciado na economia carioca e fluminense a partir do período pós-1960.

PALAVRAS-CHAVE: Instituições; Rio de Janeiro; Desenvolvimento socioeconômico.

\section{ABSTRACT}

The economic, political and social trajectory of the city and state of Rio de Janeiro is analyzed in this article, considering the formal institutionality (laws) and informal institutionality (habits and culture) that have marked this region history. We discuss the impacts of this institutionality for the establishment of the framework of dominant power in Rio de Janeiro, as well as the challenges to overcome, in the XXI century, the long process of economic decline experienced in Rio de Janeiro economy from the period after 1960 .

KEY-WORDS: Institutions; Rio de Janeiro; Socioeconomic development.

\section{Introdução}

A cidade do Rio de Janeiro, desde a sua fundação, consolidou-se institucionalmente como um espaço de articulação nacional. De início, derivou o seu dinamismo socioeconômico do fato de ser o principal porto e centro militar brasileiro e, em seguida, de ser a sede da Família Real Portuguesa, Capital do Brasil Imperial, Capital da República e centro cultural, político e econômico do país - como lócus do poder federal, centro financeiro nacional e sede de empresas públicas e privadas atuantes no território brasileiro e mesmo latino-americano.

Com essa trajetória singular, a cidade apresentou, até o início do século XX, o maior produto interno bruto (PIB) do país e constituiu o seu maior parque industrial. Contudo,

1 Registramos aqui nossos sinceros agradecimentos a Leonardo Amaral da Veiga e Ivan Gontijo Akerman, pelo cuidadoso trabalho de revisão deste artigo.

2 Professor Associado da FND/UFRJ. Coordenador do Observatório de Estudos sobre o Rio de Janeiro, vinculado ao Programa de Pós-Graduação da FND/UFRJ e cadastrado nos Grupos de Pesquisa do CNPq. E-mail: mauroosorio@uol.com.br

3 Enomomista e integrante do grupo de pesquisa Observatório de Estudos sobre o Rio de Janeiro (UFRJ). Mestrando em Planejamento Urbano e Regional, no IPPUR/UFRJ. E-mail: henriquersr@hotmail.com

4 Historiadora, vinculada ao Museu da República e integrante do grupo de pesquisa Observatório de Estudos sobre o Rio de Janeiro (UFRJ). Doutora em História, Política e Bens Culturais, pelo CPDOC/FGV. E-mail: m.versiani@globo.com 
dados do Censo de 1919 mostram que, naquele ano, o PIB industrial do estado de São Paulo já superava o carioca e era o estado paulista que liderava o processo de crescimento econômico brasileiro.

Por outro lado, apesar da economia da cidade do Rio de Janeiro apresentar, no correr de todo século XX, uma progressiva perda de posição relativa, comparativamente a São Paulo, o dinamismo econômico carioca ainda se manteve próximo ao da média nacional, entre 1920 e 1960. Isto porque, nesse período, a cidade ainda exercia a função de sede do poder federal e também se constituía como o eixo de capitalidade do país ${ }^{5}$, continuando a atrair e gerar investimentos. Carlos Lessa (2000:237-238) pontua essa questão:

\begin{abstract}
As décadas de 1920 a 1960 foram de prosperidade e de acumulação de prestígio no Rio de Janeiro. A cidade desdobrou-se em novos comportamentos e dimensões. (...) O Rio urbanizou-se em sintonia com esses novos tempos. Cabe sublinhar que foi sendo secundarizado, em termos de produção industrial, em relação a São Paulo. Desde a Primeira Guerra Mundial, São Paulo lidera a produção industrial e, apesar de crescer, o Rio vê a distância relativa das respectivas bases industriais ser ampliada, para não lembrar a espantosa diferença no campo agrícola. Porém, o Rio - concentrando serviços sofisticados, com o núcleo de comando do sistema bancário, sediando os escritórios centrais da maioria das grandes empresas, sendo o portal dos visitantes nacionais e estrangeiros, e alimentado por contínuas e crescentes injeções de gasto público - parecia ter assinado um pacto com a eterna prosperidade.
\end{abstract}

Além disso, também o antigo estado do Rio de Janeiro - considerado por Lysia Bernardes (1964) uma região polarizada do ponto de vista econômico pela cidade do Rio - era cenário de importantes investimentos federais, como a instalação da Companhia Siderúrgica Nacional; da Fábrica Nacional de Motores; da Companhia Nacional de Álcalis; e da Refinaria Duque de Caxias. Como lembra Carlos Lessa (2000:346), as decisões locacionais para tais investimentos estiveram relacionadas com a proximidade da antiga Capital Federal e também com a existência de tendência dominante, dentro do governo central, a favor da realização de um contraponto, no país, ao predomínio econômico paulista.

De fato, indicadores relativos ao PIB dos estados e regiões do Brasil mostram que, nos anos 1950, o território que abrange a atual região fluminense apresentava um crescimento médio percentual de $6,6 \%$ ao ano, bastante próximo ao da Região Sudeste, de 6,7\% ao ano, e ao do total do Brasil, de 7,1\% ao ano (Pacheco, 1998:69).

Porém, a partir de 1960, com a transferência da Capital Federal para Brasília, a cidade do Rio de Janeiro sofre um processo de fratura em sua dinâmica institucional, o mesmo ocorrendo com a Velha Província ${ }^{6}$, que deriva sua lógica econômica, pós-ciclo cafeeiro, do dinamismo existente na cidade do Rio de Janeiro e dos investimentos federais nela realizados até 1960 .

\footnotetext{
5 Utilizamos aqui o conceito de capitalidade conforme proposto por Marly Silva da Motta (2001:24), quando, partindo da formulação teórica de Giulio Argan - arquiteto, historiador da arte e prefeito comunista de Roma (1976-1979) -, define as cidades-capitais como "o lugar da política e da cultura, como núcleo da sociabilidade intelectual e da produção simbólica, representando, cada uma a sua maneira, o papel de foco da civilização, núcleo da modernidade, teatro do poder e lugar de memória”.
} 


\section{A transferência da Capital Federal: uma fratura na dinâmica institucional do Rio de Janeiro}

Utilizando a conceituação de economistas institucionalistas como Douglass North (1993), Geoffrey Hodgson (1997) e Thorsten Veblen (1934), que definem instituições como normas formais (leis e regulamentos) e informais (história, cultura, hábitos e rotinas), podemos afirmar que a cidade e o antigo estado do Rio de Janeiro, a partir da transferência da Capital Federal para Brasília, em 21 de abril de 1960, sofreram uma ruptura em seu marco institucional.

Chegamos à mesma afirmação utilizando a conceituação teórica de Paul Krugman (Krugman, Fujita e Venables, 2002), quando o autor busca analisar a existência de diferenças marcantes entre os níveis de desenvolvimento das diversas regiões que compõem o mapa do mundo. Krugman utiliza o conceito de linkages, proposto por Albert Hirschman (1958), e propõe que determinada atividade econômica pode gerar efeitos de encadeamento em determinado território e, por conseguinte, rendimentos crescentes de escala. Além disso, incorpora o conceito de causação circular cumulativa, de Gunnar Myrdall (1968), para construir a ideia de que determinada região, a partir de uma diferenciação inicial - por exemplo, a existência de um porto ou a ocorrência de algum fato histórico, mesmo que fortuito -, pode vir a desenvolver novas diferenciações em relação às demais regiões.

Tal processo envolveria uma tensão entre forças centrípetas (que gerariam dinamismo para a região em foco) e forças centrífugas (que poderiam estimular a migração de investimentos para outras regiões). As forças centrípetas seriam, fundamentalmente: os efeitos de encadeamento que um investimento em determinada atividade geraria em outras; a formação de um mercado de trabalho com tal porte que permitisse que empregadores tivessem facilidade para encontrar trabalhadores - sobretudo trabalhadores com habilidades especializadas - e vice-versa; e o que o autor denomina de meras economias externas, ou seja, qualquer tipo de facilidade extra-firma gerada pela concentração territorial.

Já as forças centrífugas estariam relacionadas a questões como: o esgotamento de fatores produtivos, por exemplo o esgotamento de terras; o aumento do custo dos aluguéis; a carência de infraestrutura; e quaisquer formas de deseconomias externas, como a poluição, a violência etc.

Dessa forma, dada região poderia apresentar um dinamismo econômico próximo ou superior ao de outras regiões, no cenário da economia de determinado país ou da economia mundial e, a partir de certo momento, por efeito da preponderância de forças centrífugas vis-à-vis às forças centrípetas, poderia sofrer uma "bifurcação" ou reversão desse dinamismo econômico.

Nessa perspectiva, pode-se afirmar que os territórios carioca e fluminense, por derivarem o seu dinamismo econômico centralmente da história da Capital e de capitalidade da cidade do Rio de Janeiro, sofreram, a partir dos anos 1960, um processo de erosão da sua importância e do seu dinamismo socioeconômico. O entendimento desse processo, no entanto, não ocorreu de forma imediata pelos próprios cariocas e fluminenses, mas somente nos anos 1980, com a inversão do processo de crescimento da economia brasileira e a crise fiscal que então se instaurou, atingindo particularmente o estado do Rio de Janeiro, pelo peso que o gasto federal ainda tinha na região. Dessa forma, até o final da década de 1970, viveu-se a doce ilusão de que a cidade do Rio de Janeiro teria assinado, nos dizeres de Carlos Lessa (2000:238), "um pacto eterno com a prosperidade".

A demora na percepção do processo de crise em que o Rio de Janeiro imergiu a partir dos anos 1960 pode ser compreendida com base em um conjunto de fatores, a começar 
pela força da cultura de capitalidade no território carioca, construída a partir da histórica centralidade política, econômica e social do Rio de Janeiro no cenário nacional. Como sugere Douglass North (1993), uma determinada conformação institucional cria hábitos e rotinas arraigados, nos quais as questões de escolha se apresentam como algo regular, repetitivo e evidente, de tal modo que cerca de $90 \%$ de nossas ações em vida seriam realizadas de forma basicamente automática. É nessa perspectiva que se pode aferir que a cultura de capitalidade do Rio de Janeiro acabou por contribuir para que nessa região não ocorresse, de forma imediata, a percepção da quebra da dinâmica institucional a partir de um fator "exógeno" (a mudança da Capital Federal para Brasília, em 1960).

Com a mesma preocupação de observar as variáveis que impactam a dinâmica institucional de determinada região, Geoffrey M. Hodgson (1997), partindo de pressupostos teóricos distintos e incorporando autores como Marx, Keynes e os institucionalistas americanos do final do século XIX e início do XX - Veblen, Commons e Mitchell ${ }^{7}$ - chega a conclusões bastante próximas às construídas por North, conforme se pode deduzir da seguinte passagem:

[Veblen] observou que as instituições têm uma qualidade de estabilidade e inércia e que tendem a manter e, portanto, a 'transmitir' as suas características importantes ao longo do tempo. As instituições são consideradas frutos e reforçadores dos processos de pensamento rotinizados, sendo partilhadas por um conjunto de pessoas numa dada sociedade. (Hodgson,1997:276)

Geoffrey Hodgson afirma também que o institucionalismo compreende os indivíduos a partir do modo como estão situados e envolvidos em seu mundo social. Dessa forma, as suas funções e preferências não seriam dadas e fixas, mas sim construídas e reconstruídas socialmente, em um contínuo processo de adaptação e mudanças. Novamente citando Veblen, Hodgson (1997:10) escreve:

Uma linha de ação habitual constitui uma linha habitual de pensamento e dá o ponto de vista através do qual os fatos e eventos são apreendidos e reduzidos a um corpo de conhecimento. As instituições criam e reforçam os hábitos de ação e pensamento: a situação de hoje molda as instituições de amanhã, através de um processo coercivo e seletivo, através da ação sobre a visão habitual do homem das coisas e dessa forma alterando ou fortificando um ponto de vista de uma atitude mental trazida do passado ${ }^{8}$.

Ou seja, por um lado, conforme identificado por institucionalistas como Geoffrey Hodgson e Douglass North, uma determinada cultura influencia a conformação de certas formas de raciocínio e de percepção do mundo, podendo dificultar a compreensão imediata de uma mudança gerada a partir de um fator exógeno - no caso aqui em exame, as consequências advindas para o Rio de Janeiro com a mudança da Capital Federal para Brasília, em 1960.

Por outro lado, o fato da transferência da Capital ter ocorrido de forma paulatina, acelerando-se somente a partir da década de 1970, no contexto do dinamismo apresentado pela economia brasileira no período 1968/1980, mascarou a lógica que se inaugurou com a mudança da Capital, não se tendo a percepção de que, por exemplo, na década de 1970, o território que hoje abriga a cidade do Rio de Janeiro apresentava um crescimento industrial

7 Geoffrey Hodgson utiliza como referência básica os institucionalistas americanos citados. No entanto, em sua obra aparece com centralidade os trabalhos de Veblen quando este propõe que se troque, como paradigma econômico, a ideia do equilíbrio advinda da Física pela ideia da evolução, utilizando a Biologia como metáfora. 
de apenas $173 \%$, contra um crescimento brasileiro em torno de $285 \%$ e, em Minas Gerais, em torno de 342\% (Rosa e Osorio, 1995).

Para uma análise da demora na percepção das consequências da transferência da Capital Federal, em 1960, para o Rio de Janeiro, deve-se levar em conta também o modelo institucional adotado para o Distrito Federal quando da implantação da República no Brasil. Ao se organizar a Capital Federal, com o advento da República, buscou-se constituíla de forma tecnocrática e conservadora, tendo como referência a cidade de Washington ${ }^{9}$, capital dos EUA. Procurou-se, assim, restringir ao máximo o espaço da política local no Distrito Federal - opção institucional que foi posteriormente reiterada na Constituição de 1946 e na Lei Orgânica do Distrito Federal de 1948. Desse modo, ficou definido que o prefeito do Distrito Federal seria nomeado pelo presidente da República e que, ao contrário das demais localidades brasileiras, as leis votadas pelos vereadores da cidade do Rio de Janeiro/Distrito Federal, que fossem depois vetadas pelo prefeito, não retornariam à Câmara Municipal, mas sim seriam analisadas pelo Senado Federal.

O esforço de neutralizar a política local naquele território não era uma novidade da República. Desde 1834, quando ocorreu a separação institucional da capital da província fluminense visando à criação do Município Neutro, já se afirmava que a Capital deveria constituir um espaço politicamente neutralizado, conforme demarcado por Carlos Lessa (2000:187-188):

Para a federação sonhada pela República, o Rio como Município Neutro era perfeito para a transmutação em Distrito Federal. Desde 1834, a cidade estava separada da província fluminense. A Capital para a República deveria manter-se politicamente neutralizada. O prefeito, escolhido pelo presidente e submetido à aprovação pelo Senado, não é o chefe do poder executivo, independente de aprovação local. É um alto funcionário de confiança do presidente que pode demiti-lo ad nutum. (...) O Rio seria o 'fórum asséptico', guardião e depositário do pacto oligárquico, o lugar de construção do marco zero da República e a moldura para dignificar a Presidência.

A forma como se organizou a institucionalidade local da cidade do Rio de Janeiro - ao lado de sua história de capitalidade - influiu para que o debate e o jogo político local perdessem força na região, contribuindo assim para a conformação de um particular quadro de carência no tocante à reflexão local.

Desse modo, constituiu-se com força na cidade do Rio, conforme analisado por Marly Silva da Motta $(2000 ; 2001)$, duas lógicas políticas. Uma bastante focada nas questões nacionais e radicalizada no que se refere à representação da cidade na Câmara Federal e no Senado - o que pode ser visto, por exemplo, no fato de disputarem o Senado, pelo Distrito Federal, em 1958, Afonso Arinos, prócer da UDN nacional e deputado por Minas Gerais, e Lutero Vargas, simbolizando o getulismo; ou no fato de, em 1962, terem participado da disputa pela representação da Guanabara no Senado, Juracy Magalhães, então governador da Bahia e liderança nacional da UDN, e Aurélio Viana, deputado federal por Alagoas e líder da esquerda nacionalista na Câmara dos Deputados.

Já a outra lógica, da política local, seria determinada pela ausência de eleições diretas locais para prefeito e pelo pouco poder dos vereadores eleitos para interferir na vida da cidade. Veja-se ainda que, no período entre 1946 e 1960, as eleições para a representação federal na cidade do Rio de Janeiro/Distrito Federal realizaram-se centralmente em torno de poucos partidos e com forte participação de líderes políticos que simbolizavam o debate nacional,

9 Sobre o assunto, ver Freire (2000) e Motta (2001). 
ao passo que o jogo político local ocorreu de forma fragmentária e clientelista, num quadro de forte pulverização das agremiações partidárias. Nos anos 1950, por exemplo, enquanto a representação federal do Rio limitava-se a quatro partidos com dois ou mais membros eleitos, a representação local fracionava-se em onze partidos. Além disso, entre os quatro partidos que disputavam a representação federal, era grande a centralidade do PTB e da UDN, enquanto a representação do PSD carioca (maior partido do Congresso Nacional nos anos 1950, com posição mais centrista) limitava-se a um único parlamentar. Isso deixava em evidência o polarizado debate nacional reproduzido com particular força no Rio de Janeiro, nesse período, liderado, por um lado, por Getúlio Vargas, Leonel Brizola e João Goulart e, por outro, por Carlos Lacerda. Já a lógica política local, ao contrário da lógica política nacional, teria menos peso e importância na cidade do Rio de Janeiro, ocorrendo de forma marcadamente fragmentária ${ }^{10}$.

Assim, a forma como se organizou institucionalmente o Distrito Federal no território carioca teve também relação direta com o fato de, na segunda metade dos anos 1950, as reflexões e proposições sobre os rumos e estratégias para a cidade do Rio de Janeiro, após transferência da Capital, ocorrerem de maneira bastante pobre e com muito pouca sensibilização social a partir de 1960, sem que se atentasse imediatamente para os impactos e consequências desse processo para o Rio de Janeiro.

A esse respeito, cabe destacar que a transferência da Capital para Brasília já estava definida na Constituição desde 1891, permanecendo durante anos como "letra morta". Isso fez com que a proposta lançada por Juscelino Kubitschek, durante sua campanha presidencial e quando assumiu o governo federal, tenha sido tratada com desdém por diversos setores da sociedade. Mesmo a UDN, partido de oposição, votou todas as leis propostas por JK que visavam permitir a criação de Brasília. O objetivo era, posteriormente, desmoralizar JK, afirmando que a UDN tinha aprovado todas as solicitações do presidente para a construção de Brasília, mas que ele não cumprira a promessa de transferir a Capital ${ }^{11}$.

A descrença quanto à efetivação da mudança da Capital levou também a que ocorresse apenas um único debate público sobre os rumos do Rio de Janeiro após a transferência da Capital para Brasília. Organizado pelo jornal Correio da Manhã, em 1958, esse debate compreendeu várias entrevistas com líderes empresariais, comunitários, intelectuais e políticos, em uma série denominada "O que será do Rio"12.

Assim, na Belacap ${ }^{13}$, em função de sua trajetória de cidade-Capital e da forma como foi historicamente organizada do ponto de vista político-institucional, conforme pontuado por Arnaldo Niskier (Guanabara, 1970:15), a vivência dos problemas nacionais reduziam "a pálidos reflexos os problemas locais. Depois da mudança da Capital para o Planalto, o povo carioca descobriu que só conhecia de si mesmo e de sua cidade a visão do turista apressado."

Esta questão também é apontada em depoimento de Villas-Boas Corrêa ao CPDOC (Ferreira, 1998:55), nos seguintes termos:

Acho que a bancada do Rio de Janeiro, como o Rio era Capital, se dissolvia muito, não tinha muita identidade. Até porque o prefeito do Rio era nomeado (...). A grande verdade é a seguinte: cobria-se mal a política carioca, porque a política nacional, que era feita aqui no Rio de Janeiro, abafava a política local.

10 Sobre o assunto, ver Osorio (2005). Para uma discussão sobre o conceito de clientela, ver Diniz (1982).

11 Sobre o assunto, ver depoimento de Luiz Alberto Bahia, anexo à tese de doutorado de Mauro Osorio

12 A série referida também se encontra disponível no anexo da tese de doutorado de Mauro Osorio (2004).

13 Como era então chamada a Guanabara, nos anos 1960, em oposição à Novacap (Brasília). 
No mesmo sentido que na cidade do Rio de Janeiro, no antigo estado do Rio a presença da Capital se fazia sentir, conforme mostra Marieta de Moraes Ferreira (1991) quando pontua a existência de uma dificuldade de interlocução entre as elites econômicas escravagistas da Velha Província e as elites políticas, de viés mais nacional, como Alberto Torres e Nilo Peçanha. Essa dificuldade de interlocução teria obstacularizado a implantação de estratégias econômicas quando da decadência da cafeicultura na região, ao longo da segunda metade do século XIX.

A questão das elites políticas do antigo estado do Rio terem um marcante viés nacional apresentará continuidade, em nosso entendimento, até os anos 1950, o que se evidencia pela presença de personagens como Macedo Soares, Prado Kely, Raul Fernandes e mesmo Amaral Peixoto, que migrou da política carioca para a do antigo estado do Rio, a partir de seu relacionamento com Getúlio Vargas, mas manteve participação e influência na política carioca ${ }^{14}$.

A importância da articulação entre as elites políticas e econômicas de uma região, para a alavancagem de um processo de desenvolvimento econômico, é bem pontuada em Otávio Dulci (1999), quando o autor analisa essa relação como um elemento-chave da estratégia engendrada em Minas Gerais, a partir da década de 1940 e 1950, que gerou um articulado arcabouço institucional de fomento ao desenvolvimento daquele estado ${ }^{15}$. Assim, a dificuldade de interlocução entre as elites econômicas e políticas na Velha Província certamente contribuiu para que a lógica econômica na região, pós-ciclo cafeeiro, viesse a depender de investimentos federais e da Capital da República, tanto ou mais do que a própria cidade do Rio de Janeiro. Contribuiu também para que a transferência da Capital para Brasília representasse, no antigo estado do Rio de Janeiro, da mesma forma que no território carioca, um marco de reversão de dinamismo ${ }^{16}$.

\section{Transferência da Capital x Equívocos no fomento ao desenvolvimento regional}

Nos anos 1960, tendo em vista a conjunção de fatores enunciados, que inclui a história de Capital e de capitalidade da cidade do Rio de Janeiro; a sua trajetória institucional; a radicalização vigente na política nacional; e ainda o fato de que o processo de transferência da Capital se consolidou de forma lenta e gradativa ao longo dos anos 1960 e 1970, fez-se então hegemônica a percepção de que o Rio continuaria a ser a Belacap e a Capital de fato. Isso levou, inclusive, a que os dois primeiros governos da Guanabara - Carlos Lacerda (1960-1966) e Negrão de Lima (1966-1971) - realizassem uma política de modernização urbana com base no entendimento de que tal política, per se, garantiria a centralidade do desenvolvimento carioca.

Do ponto de vista da formulação de uma política explícita de desenvolvimento econômico - e expressando a falta de massa crítica sobre a realidade local - desenvolveu-se, na Guanabara, nos governos Carlos Lacerda e Negrão de Lima, e com continuidade no governo

14 Sobre o peso da participação de Amaral Peixoto nas negociações sobre a nova institucionalidade carioca, quando da transferência da Capital para Brasília, ver, por exemplo, Motta (2000:32).

15 Em Minas Gerais, visando fomentar o desenvolvimento regional e realizar pesquisas, criou-se um conjunto de instituições, incluindo: a Fundação João Pinheiro, voltada para a realização de pesquisas sobre a realidade mineira; um programa de Mestrado e mais recentemente de Doutorado, denominado CEDEPLAR e vinculado à Universidade Federal de Minas Gerais; a Fundação INDI, órgão para a promoção econômica de Minas Gerais; e o Banco de Desenvolvimento Econômico de Minas Gerais - BDMG.

16 Acreditamos que a Velha Província tenha sofrido com a transferência da Capital de forma mais pesada do que a cidade do Rio de Janeiro, não só pela dependência econômica já apontada, mas também pela instabilidade político-institucional vivenciada naquela região, entre 1960 e 1964, após a morte do governador Roberto da Silveira; pela posterior cassação do governador Badger da Silveira; e pelo fato dos governadores nomeados pelo governo militar terem permanecido no cargo, em média, por apenas dois anos. 
Chagas Freitas (1971-1975), uma política de fomento focada na indústria, particularmente na organização de distritos industriais, conforme tese defendida pela representação patronal da indústria da Guanabara. Tal política realizou-se, fundamentalmente, com base em dados e pressupostos equivocados, sem que se tivesse uma preocupação com o entendimento rigoroso e embasado sobre as potencialidades da região, resultando, ao final da década, em um rotundo fracasso.

A tese defendida pela representação patronal da indústria da Guanabara sugeria que, naquela região, da mesma forma que então ocorria na cidade de São Paulo e em outras metrópoles mundiais, estaria ocorrendo um derramamento do processo de industrialização, do seu núcleo central para a periferia - tendo em vista o crescimento do porte das indústrias, no auge da segunda revolução industrial -, sendo, portanto, de fundamental importância para a nascente cidade-estado da Guanabara a organização de uma política de oferta de terrenos e de infraestrutura, que retivesse a indústria instalada dentro do território carioca. Apresentou-se, como argumento, o fato de, nos anos 1940, 1950 e início dos 1960, a indústria do antigo estado do Rio de Janeiro ter crescido acima da média nacional. Porém não se levou em devida consideração que, especificamente na Velha Província, isso não ocorria fundamentalmente pela transferência de plantas industriais privadas da cidade do Rio para o antigo estado do Rio de Janeiro, mas, sim, pela criação, naquela região, de empresas estatais, pelo governo federal ${ }^{17}$.

Outro pressuposto equivocado que instruiu as políticas implementadas pelos governos da Guanabara foi o de que Brasília não se consolidaria como Capital e, por esse motivo, com a modernização da Belacap, o setor serviços tenderia a se manter na Cidade Maravilhosa, não demandando por políticas específicas de fomento ${ }^{18}$.

Tal pressuposto e o foco econômico dos três governos da Guanabara, entre 1960 e 1975, no setor industrial e em uma política de distritos industriais - inclusive sendo constituída, para tanto, no início do governo Lacerda, uma empresa de fomento chamada Companhia Progresso da Guanabara (COPEG) -, estavam em consonância com os interesses da representação industrial carioca (uma das poucas instituições a se inserir, de forma organizada e com forte hegemonia, no rarefeito debate local), mas, objetivamente, não deram conta da problemática da reinserção estratégica dessa unidade federativa no cenário da economia brasileira.

De fato, a política focada em distritos industriais organizada para a Guanabara fracassou. No curso do governo Lacerda, só ocorreu a ocupação, por indústrias, de $1 \%$ da área inicialmente prevista para o total dos distritos industriais, então criados na Avenida das Bandeiras e em Santa Cruz (Guanabara, 1970:46). No governo Negrão de Lima, a política de distritos industriais também não obteve resultado significativo, seja pela não ocupação do novo distrito por ele criado, a Fazenda Botafogo, seja porque o distrito industrial de Santa Cruz continuava praticamente desocupado.

Da mesma forma, essa política não apresentou, no período Chagas Freitas, resultados expressivos, apesar de, do ponto de vista da estratégia governamental, ter ocorrido uma

\footnotetext{
17 Sobre o assunto, ver Osorio (2005). Vale pontuar que a carência de reflexão e de organização de dados no âmbito regional e a tradição do Rio de Janeiro de privilegiar o debate de temas nacionais e internacionais fazem com que, em diversos momentos, ao ser observada a existência de uma determinada tendência em outras regiões do planeta, e ao primeiro dado que aponte que aparentemente o mesmo estaria ocorrendo em nossa região, passemos a trabalhar com a mesma hipótese. Isso aconteceu quando da implantação da política de distritos industriais na Guanabara e, mais recentemente, com alguns autores apontando uma significativa interiorização da economia fluminense. No segundo caso, não se levou devidamente em conta que o crescimento do PIB no interior fluminense derivava centralmente da extração de petróleo em alto mar, não tendo gerado estrutura produtiva significativa em terra, no interior do estado.
}

18 Matérias publicadas no jornal $O$ Globo, logo após a mudança da Capital para Brasília, mostram o carioca comemorando o acontecimento. A comemoração baseava-se no fato de que, após longos anos, finalmente o Rio poderia eleger o seu governador e que, pela hipótese da não consolidação de Brasília, a cidade manter-se-ia como a "Capital de fato". 
amplificação de foco. Isso é o que mostra, por exemplo, depoimento de José Augusto Assumpção Brito (apud Osorio, 2005, Conclusão), segundo o qual a consolidação dos investimentos de infraestrutura que permitiram que o Distrito Industrial de Santa Cruz viesse a funcionar de fato só ocorreria ao final do governo Chagas Freitas. Além disso, de acordo com Assumpção Brito, a política de distritos industriais não teria importância significativa no crescimento industrial carioca ocorrido nos anos 1970, que, segundo ele, teria derivado centralmente do milagre econômico ${ }^{19}$. Por outro lado, a partir da análise dos documentos Economia Industrial do Novo Estado do Rio de Janeiro (Barros, 1975) e Tendências de crescimento da Guanabara (Ideg, 1974), é possível chegar à mesma conclusão. De acordo com Barros, por exemplo, no ano de 1973 existiria, para o total do bairro de Santa Cruz, apenas 15 indústrias, o que representava uma participação de $0,6 \%$ no total do número de estabelecimentos industriais existentes na cidade do Rio de Janeiro. Além disso, o autor analisa que o bairro de Jacarepaguá, onde Chagas Freitas estabeleceu um novo distrito industrial, possuiria, em 1973, apenas $1,83 \%$ do total de estabelecimentos industriais da cidade (Barros, 1975:156).

Dessa forma, nenhum dos três governos da Guanabara conseguiu articular uma reversão do processo de "bifurcação" - utilizando a conceituação de Paul Krugman (2002) - que ocorreu em 1960, no território carioca.

Por sua vez, após a fusão da Guanabara com o antigo estado do Rio, em 1975, os governos persistiram em, por um lado, apresentar uma visão equivocada sobre quais deveriam ser as estratégias de desenvolvimento econômico para a região - no governo Faria Lima, por exemplo, a preocupação centrou-se no setor agrícola, apesar da diminuta participação desse setor no PIB carioca. Por outro lado, adotaram um foco pontual, sem estudos setoriais e uma adequada estratégia e coordenação de políticas. Ou, ainda, simplesmente dispensaram a formulação de quaisquer políticas de desenvolvimento econômico.

Para uma análise sobre a carência de uma adequada estratégia de desenvolvimento econômico para a cidade do Rio de Janeiro, e posteriormente, após a fusão, para o estado do Rio de Janeiro, acreditamos ser interessante citar a seguinte consideração de Raphael de Almeida Magalhães, vice-governador do primeiro governo da Guanabara e coordenador do Programa de Ações Federais no Rio de Janeiro, no correr dos dois governos de Fernando Henrique Cardoso:

A criação do Estado da Guanabara em si mesma não poderia dar conta das causas que determinaram a decadência da cidade. Teve entretanto o mérito de permitir a autonomia política da cidade, cujo governo pôde, com verdadeiro empenho, tentar, ao menos, recuperar a qualidade dos serviços básicos, enfrentando, com êxito parcial, alguns dos mais agudos problemas de infraestrutura herdados da época da dominação federal.

A verdade é que a simples autonomia política não bastava para a viabilização de um projeto de restauração substitutiva da base produtiva da cidade e da sua região, afetada com a perda irreversível da condição de metrópole nacional. (...)

Redescobrir funções reorganizadoras das atividades econômicas continua sendo, assim, desde a década dos 50, o verdadeiro desafio para a cidade e sua região. Identificá-las, agora, se inscreve, além do mais, no complexo

\footnotetext{
19 José Augusto Assumpção Brito apresenta longa trajetória de atuação como técnico e dirigente em instituições vinculadas à economia da Guanabara e do antigo estado do Rio de Janeiro. Nos anos 1960, trabalhou como técnico na COPEG. Na primeira metade dos anos 1970, atuou vinculado à Companhia de Desenvolvimento Industrial do antigo estado do Rio de Janeiro. A partir de 1975, com a fusão, dirigiu a CODIN, Companhia de Desenvolvimento do novo estado do Rio de Janeiro, por um período de dez anos. Posteriormente, participou dos governos Saturnino Braga, Moreira Franco e Marcelo Alencar, tendo sido ainda, no início dos anos 1990, presidente do Sebrae nacional.
} 


\section{Um golpe que favoreceu o clientelismo e a degradação econômico-social do Rio de Janeiro}

Entendemos que a trajetória econômica pós-1960 do Rio de Janeiro foi decisivamente influenciada pela transferência da Capital para Brasília; pela história de capitalidade da cidade do Rio; pela constituição de seu desenho político-institucional local; e pela consequente carência de reflexão e pelos equívocos nas estratégias regionais. Além disso, a cidade e o estado do Rio de Janeiro sofreram profunda degradação em sua lógica política, a partir do golpe de 1964 e das cassações, que atingiram com particular gravidade a cidade do Rio.

De fato, pela centralidade política do Rio de Janeiro, no cenário brasileiro, a sua representação federal foi fortemente atingida no processo de cassações. A polarização existente no debate político nacional e o papel central do Rio nesse debate, principalmente nos anos 1950 e na primeira metade dos anos 1960, redundaram em que a representação federal da cidade apresentasse a marca da radicalização e que se circunscrevesse a poucos partidos, basicamente o PTB e a UDN.

Assim, logo após o golpe de 1964, por um lado, o PTB e a esquerda como um todo sofreram pesadamente o processo de cassações, sendo que, no caso da cidade do Rio, entre os dez deputados federais eleitos pelo PTB, em 1962, oito foram cassados. Por outro lado, pelo fato de Carlos Lacerda romper com o regime militar no correr da década de 1960, a UDN carioca também foi fortemente atingida pelas cassações, provocando-se, no conjunto, uma desarticulação da lógica nacional nessa região e abrindo-se espaço para que Chagas Freitas e a sua política de clientela articulada à lógica local conquistassem particular hegemonia, primeiro na cidade e posteriormente no estado do Rio ${ }^{20}$. Essa lógica fez história ao longo dos anos, conforme podemos verificar pela declaração da governadora Rosinha Garotinho (2003-2006), publicada no jornal O Globo, de 10 de outubro de 2003, em que ela analisa que, na região fluminense, após o chaguismo e o brizolismo, "por que não o garotismo?".

Ou seja, na cidade do Rio de Janeiro e, posteriormente, no novo estado do Rio viria a ocorrer, através dos processos históricos de permanências e mudanças, a coexistência entre uma lógica nacional cada vez mais inorgânica e uma lógica clientelista e fragmentária crescentemente hegemônica no plano estadual. Tal realidade gera um marco institucional que desestrutura com particularidade o poder público na região e dificulta a organização consistente de estratégias e políticas regionais.

Assim, a transferência da Capital para Brasília, em 1960, e a consolidação dessa transferência no correr da década de 1970; a carência de reflexão regional e de adequadas estratégias regionais de fomento ao desenvolvimento; ao lado da particular degradação política que a cidade e o estado do Rio sofreram em consequência do golpe de 1964 são fatores absolutamente centrais no processo de degradação econômico-social do atual estado do Rio de Janeiro, no cenário brasileiro.

Do ponto de vista econômico, esse processo de degradação pode ser verificado a partir de um conjunto de indicadores. Através das Contas Regionais do Brasil, divulgadas pelo

20 Sobre o assunto, ver dissertação de mestrado de Maria Helena Versiani (2007). Nessa dissertação, é feita uma análise dos posicionamentos da bancada federal de representação da cidade do Rio de Janeiro, nos anos de 1962 e de 1970. Os discursos da bancada eleita em 1962 eram hegemonicamente referenciados no debate brasileiro. Já os discursos da bancada federal eleita em 1970, tendo em vista as cassações ocorridas, apresentavam uma linha de defesa de questões pontuais e clientelistas. 
IBGE, por exemplo, entre 1970 e 2013, o PIB do atual estado do Rio de Janeiro passou de uma participação no PIB nacional de $16,7 \%$ para uma participação de $11,8 \%$, a maior perda entre todas as unidades federativas brasileiras ${ }^{21}$.

Na mesma linha, de acordo com dados do Ministério do Trabalho (RAIS/MTE), o estado do Rio de Janeiro apresentou, entre 1985 e 2014 (a série mais longa disponível com a mesma metodologia), um crescimento do emprego formal de $73,6 \%$, contra um crescimento no total do país de $141,9 \%$, o menor crescimento entre todas as unidades federativas brasileiras.

A particular estagnação do conjunto da economia carioca e fluminense evidencia-se também no fato de que o estado do Rio de Janeiro, que apresentava, em 1985, a segunda posição, entre todas as unidades federativas brasileiras, no que tange ao número de empregos formais gerados no conjunto das atividades públicas e privadas, estando atrás apenas de São Paulo, tenha sido, desde 1999, ultrapassado por Minas Gerais, caindo para a terceira posição no ranking das unidades federativas.

No que se refere ao emprego especificamente na indústria de transformação, a perda foi ainda mais acentuada. O Rio de Janeiro passou da segunda posição, em 1985, para a sexta posição, em 2014, sendo ultrapassado por Minas Gerais, Rio Grande do Sul, Paraná e Santa Catarina.

Igualmente expressivo é o fato de Minas Gerais ter ultrapassado o estado do Rio de Janeiro, em 2004, no que diz respeito à receita gerada pelo imposto estadual de ICMS, ampliando assim a dependência do estado do Rio de Janeiro em relação às receitas de royalties do petróleo ${ }^{22}$.

Nesse processo, o estado do Rio de Janeiro ficou com um ralo adensamento produtivo e grande concentração em refino de petróleo e siderurgia. Essa rala densidade produtiva pode ser vista principalmente na periferia metropolitana e no interior fluminense ${ }^{23}$. No ano de 2014, através de dados da Rais/MTE, verificamos que, no Brasil e na Região Sudeste, os empregos formais públicos representavam, respectivamente, 20,05\% e $15,41 \%$ do total de empregos formais. Já entre os 91 municípios do interior fluminense e da metrópole (excluindo-se a cidade do Rio de Janeiro), encontramos 56 municípios com o peso do emprego público superior ao encontrado para o Brasil, sendo que 43 municípios apresentavam percentual acima de 30\%, 19 municípios apresentavam percentual acima de $40 \%$ e em 10 municípios o peso do emprego privado no total do emprego formal municipal não chegou a representar $50 \%$.

Deve-se destacar que a cidade do Rio de Janeiro, apesar ter sido Capital Federal por quase duzentos anos e da forte presença em seu território do serviço público federal - como, por exemplo, das Forças Armadas e de Universidades públicas federais - apresentava, em 2014, um peso do emprego no setor público no total de empregos formais de $18,65 \%$.

Com relação aos indicadores sociais e de infraestrutura, também verificamos particular degradação da região fluminense no cenário federativo. Dados do Censo do IBGE de 2010 mostram, por exemplo, uma situação particularmente grave do ponto de vista habitacional.

21 Em 1975, como sabemos, ocorreu a fusão entre a Guanabara e o antigo Estado do Rio de Janeiro. Dessa forma, nos dados de PIB aqui apresentados, referentes ao ano de 1970, estão somados o PIB do antigo estado do Rio de Janeiro com o PIB da Guanabara, permitindo a comparação com o PIB do estado do Rio pós-fusão.

22 Este dado foi calculado a partir de indicadores sistematizados pelo Conselho Nacional de Política Fazendária do Ministério da Fazenda (Confaz), em pesquisas realizadas pelo Observatório de Estudos sobre o Rio de Janeiro, grupo de pesquisa cadastrado no CNPQ e vinculado ao Programa de Pós-Graduação em Direito da Universidade Federal do Rio de Janeiro.

23 A Região Metropolitana do Rio de Janeiro é composta pelos seguintes 21 municípios: Belford Roxo; Cachoeira de Macacu; Duque de Caxias; Guapimirim; Itaboraí; Itaguaí; Japeri; Magé; Maricá; Mesquita; Nilópolis; Niterói; Nova Iguaçu; Paracambi; Queimados; Rio Bonito; Rio de Janeiro; São Gonçalo; São João de Meriti; Seropédica; e Tanguá. 
Organizando-se um ranking, por estado brasileiro, do percentual de pessoas moradoras de favelas, em relação ao total de habitantes, verifica-se que o estado do Rio apresentou, em 2010, um percentual de $12,7 \%$, o terceiro maior entre todas as unidades federativas, melhor apenas do que o Pará e o Amapá, que apresentaram o primeiro e segundo maior percentual. Este percentual era de 6,62\% no estado de São Paulo e de apenas 3,07\% em Minas Gerais.

Outro exemplo, também com base nos dados do Censo de 2010 do IBGE, é o expressivo percentual de jovens entre 18 e 24 anos de idade que não estudam nem trabalham, na cidade do Rio e principalmente em suas áreas periféricas. Na Zona Suburbana, esse percentual, em 2010, chegava a ser de 38,8\% na área do Jacarezinho; de 32,9\% no Complexo do Alemão; de 32,5\% na Penha; de 30,1\% em Anchieta; de 30,0\% na Pavuna; e de 29,5\% na Maré. Na Zona Oeste, atingia 38,4\% em Santa Cruz; 35,1\% em Bangu; e 33,0\% em Guaratiba.

Além disso, enquanto na Região Sudeste o percentual de nem-nens entre os jovens com 18 a 24 anos de idade era, em 2010, de $24,2 \%$, entre os 21 municípios da RMRJ, 16 apresentavam percentual superior a $30 \%$, sendo que em 8 municípios da metrópole carioca o número de jovens sem estudar nem trabalhar era igual ou superior a $1 / 3$ dos jovens. No interior fluminense, 62 entre os 71 municípios da região apresentavam percentual de nem-nens superior ao verificado para o conjunto da Região Sudeste.

$\mathrm{Na}$ área de educação, o péssimo posicionamento do estado do Rio de Janeiro no cenário federativo; da cidade do Rio de Janeiro comparativamente às demais capitais brasileiras; e dos municípios fluminenses em face à situação verificada nos municípios da Região Sudeste e do Brasil, no ano de 2013, pode ser verificado, por exemplo, com base nos resultados do Índice de Oportunidades da Educação Brasileira-loeb, organizado pelo Centro de Liderança Pública-CLP, com apoio das Fundações Lemann e Roberto Marinho ${ }^{24}$.

Organizando um ranking dos resultados do loeb para as unidades federativas, em 2013, vemos que o estado do Rio de Janeiro encontrava-se apenas na $15^{\mathrm{a}}$ posição. Na mesma direção, em um ranking das capitais, a cidade do Rio encontrava-se na $11^{\mathrm{a}}$ posição.

Com base nesse mesmo índice, o município fluminense mais bem colocado, entre 1.620 municípios da Região Sudeste, é Comendador Levy Gasparian (Região Centro-Sul Fluminense), na $500^{a}$ posição. Em segundo lugar aparecem os municípios de Santo Antônio de Pádua, na $713^{\mathrm{a}}$ posição e Aperibé, na $993^{\mathrm{a}}$ posição (ambos da Região do Noroeste Fluminense $)^{25}$. Todos os demais 89 municípios fluminenses encontravam-se além da $1000^{\mathrm{a}}$ posição, sendo que 61 deles encontravam-se atrás da $1500^{\mathrm{a}}$ posição.

Por último, entre os 20 municípios pior colocados no ranking dos 1620 municípios pesquisados da Região Sudeste, infelizmente 18 são do estado do Rio de Janeiro.

A trajetória do estado do Rio de Janeiro no pós-1960 também conduziu a uma situação particularmente grave no que tange à questão da segurança pública, com a constituição de "estados paralelos" na metrópole carioca, em um nível de institucionalização inexistente em outras metrópoles brasileiras e mesmo da América Latina, sendo consequência da

\footnotetext{
24 Esse índice procura observar a qualidade da educação em cada município brasileiro, levando em consideração os dados disponíveis no que diz respeito aos resultados da educação pública e privada, de ensino fundamental e médio. Leva em conta ainda informações como o número de crianças e adolescentes em idade escolar e fora da sala de aula. Procura também, dar ênfase à necessidade de integrar os ensinos fundamental e médio, dentro da lógica de estimular a criação, em cada localidade, de um sistema municipal de educação. A metodologia completa desse índice está disponível no link: http://www.ioeb.org.br/pagina/metodologia

25 Em algumas análises e debates sobre o estado do Rio de Janeiro, a Região Noroeste Fluminense é apontada como a mais complicada do ponto de vista socioeconômico. De fato, essa região é a que apresenta o menor PIB per capita, entre todas as oito Regiões de Governo do estado do Rio de Janeiro. No entanto, ao olharmos com mais cuidado o conjunto dos indicadores socioeconômicos dos 92 municípios fluminenses e das Regiões de Governo, verificamos que a região com maior degradação socioeconômica é a Região Metropolitana, particularmente a sua periferia. Sobre o assunto, ver Sobral, 2015.
} 
particular desestruturação ocorrida na polícia fluminense com a instauração do marco institucional que passa a existir no Rio após o golpe de 1964.

Sobre esse aspecto, vale citar dois artigos analíticos: o de Mauro Osorio, intitulado Estado do Rio de Janeiro: estagnação de longo curso e possibilidades de reversão, publicado no Jornal dos Economistas, do Corecon/RJ, em 2008, e o do jornalista Xico Vargas, intitulado $O$ caminho de ouro, publicado no site No Mínimo, em 2006.

No primeiro, tem destaque o fato de policiais de outros estados brasileiros - incluindo estados muito violentos, como Pernambuco -, que vieram para o Rio de Janeiro compor a Força Nacional, por ocasião do Panamericano em 2007, terem, de acordo com matérias de jornais à época, ficado estupefatos com o nível de armamento verificado em áreas dominadas pelo tráfico no Rio, bem como com o elevado grau de rejeição dos moradoras de favelas em relação às forças policiais estaduais.

No segundo artigo, Xico Vargas aponta o alarmante nível de institucionalização da corrupção então verificada na estrutura de segurança pública estadual. Diz ele: "De qualquer maneira, para policiais (os da banda boa) não há dúvida de que todas as delegacias têm dono e quotas de arrecadação".

\section{0 Rio no século XXI: potencialidades, dilemas e desafios}

No início do século XXI, a economia do estado do Rio de Janeiro volta a apresentar, após décadas, uma aproximação com a trajetória da economia brasileira. Isto tem relação com a atração de investimentos para a região, que se inicia em meados dos anos 1990 e que começa a impactar os indicadores econômicos, principalmente a partir do final da primeira década do século XXI. Entre os grandes investimentos que têm lugar no estado do Rio de Janeiro, destacam-se, por exemplo, a chegada de montadoras de automóveis à Região do Médio Paraíba; a implantação da Rio Polímeros, em Duque de Caxias, objetivando a criação na região de um polo de gás-químico ${ }^{26}$; a reativação da indústria naval; a ampliação de investimentos pela Petrobras até o ano de 2014; a instalação, na cidade do Rio de Janeiro, de novas empresas petrolíferas; a consolidação do parque tecnológico da UFRJ, em torno do complexo de petróleo e gás; a instalação de uma planta siderúrgica no distrito industrial de Santa Cruz; investimentos na Fiocruz e no Instituto Vital Brazil; além dos investimentos derivados da política de atração de megaeventos.

A aproximação com a trajetória econômica brasileira pode ser verificada, por exemplo, no fato de que, entre 2008 e 2014, enquanto o emprego formal na Região Sudeste e no Brasil cresceram, respectivamente, $21,6 \%$ e $25,7 \%$, no ERJ cresceu $25,0 \%$.

No entanto, o conjunto dos indicadores apontados nesse artigo mostra a continuidade de uma grave situação socioeconômica no estado do Rio de Janeiro, que é reforçada com a crise a partir de 2015, que atinge particularmente o estado, não só pela herança ainda existente da trajetória pós-1960, como também pela forte queda do preço internacional do petróleo e seu impacto para as receitas públicas de royalties no âmbito do estado do Rio de Janeiro e de seus municípios, em especial as Regiões Norte e das Baixadas Litorâneas.

26 No ano de 1995, o governo Fernando Henrique Cardoso, em face da decadência econômico-social do estado do Rio de Janeiro e da importância social e simbólica dessa região, criou um Conselho de Ações Federais no estado, presidido pelo presidente da República e tendo como secretário executivo o advogado Raphael de Almeida Magalhães. Esse Conselho definiu, entre suas prioridades: a criação de um polo petroquímico com base no gás natural, em Duque de Caxias; o desenvolvimento de um porto de contêiner, em Itaguaí, cujo projeto era o de ser o maior porto da América Latina; e a criação de um grupo de trabalho para atuar em prol da conquista, pelo Rio de Janeiro, da função de sede das Olimpíadas de 2004. Essa iniciativa contribuiu para a política de atração de megaeventos, que redundou no Rio de Janeiro ser a sede dos Jogos Panamericanos, em 2007; dos Jogos Mundiais Militares, em 2011; da Rio+20, em 2012; da Jornada Mundial da Juventude, em 2013; uma das principais sedes da Copa do Mundo, de 2014; e também sediar as Olimpíadas de 2016. 
Para a superação definitiva dessa condição de precariedade e a constituição de um círculo virtuoso no estado do Rio de Janeiro, deve-se ter em conta que é necessário mobilizar mais a academia no que diz respeito às reflexões sobre o estado e seus municípios. De fato, a tradição, no estado do Rio, até os dias atuais, de se ter particular preocupação com os temas nacionais vis-à-vis os temas locais, é confirmada, por exemplo, no fato de que inexistem, em quaisquer dos Programas de Mestrado e Doutorado em Economia das universidades instaladas no estado, linhas permanentes de pesquisa em Economia Regional.

A carência de reflexão dificulta o debate na sociedade sobre a real agenda que permitiria a constituição de um círculo virtuoso no Rio de Janeiro e a diminuição das desigualdades sociais e territoriais. Além disso, permite particular liberdade para atuação de lobbies e grupos de interesse, como ocorreu nos anos 1960 e na primeira metade dos anos 1970, quando os governos Lacerda, Negrão e Chagas incorporaram a equivocada tese de que a indústria guanabarina estaria migrando para o antigo estado do Rio e a prioridade da política econômica local seria estabelecer condições que permitissem retê-la no território carioca. Em período mais recente, um exemplo é o forte lobby dos Grupos Multiterminais e Libra, proprietários dos terminais de conteiners localizados no Porto do Rio, que dificulta uma política de apoio ao crescimento do terminal de conteiner localizado em Itaguaí e que pode ser peça chave para atrair atividades produtivas para a periferia metropolitana, fazendo assim com que ela deixe de ser dormitório.

No que diz respeito ao adensamento produtivo, do ponto de vista setorial, é importante examinar e aprofundar as pesquisas e debates sobre as atividades e os complexos produtivos com maior potencialidade no estado do Rio de Janeiro. Em primeiro lugar, é fundamental ampliar a discussão sobre o papel que o setor petróleo e o que podemos denominar de complexo do petróleo e gás - extração de petróleo; partes, peças e equipamentos; indústria naval; inovação; projetos de engenharia; convenções, eventos e turismo de negócios em geral; serviços de apoio etc. - podem significar para o desenvolvimento socioeconômico do estado do Rio de Janeiro nas próximas décadas.

É óbvio que a total prioridade deve ser para a busca de energias renováveis e o estímulo a atividades econômicas, como, por exemplo, o desenvolvimento de carros elétricos. No entanto, o que especialistas afirmam, como o professor titular Adilson Oliveira, da UFRJ, é que o mundo ainda continuará dependente do petróleo nas próximas décadas. Além disso, análises, não só na academia, mas também nas empresas do setor petróleo, como a Shell, que mantém como prioritários os seus investimentos no Brasil, apontam que a produtividade na extração do petróleo no pré-sal tem crescido muito e que essa extração permanece absolutamente viável. Sobre a competitividade e produtividade do pré-sal, vale a pena trazer trecho de entrevista do quadro de carreira e ex-diretor de Exploração e Produção da Petrobras, Guilherme Estrella, e que chefiou, de 2003 a 2012, a equipe que descobriu o pré-sal. A entrevista foi publicada no jornal Estado de S. Paulo, de 2 de março de 2016:

\begin{abstract}
A Petobras produz 2 milhões de barris por dia nas Bacias de Santos e Campos, na frente do mercado consumidor. Nós produzimos a US\$ 8 o barril no présal, por usar a infraestrutura vizinha da Bacia de Santos. É uma vantagem competitiva. As grandes empresas mundiais produzem 4 milhões de barris por dia em campos espalhados no mundo, com operação caríssima.
\end{abstract}

Assim, deve-se identificar cuidadosamente qual a real presença do complexo do petróleo e gás no Rio de Janeiro e qual política deve ser aprimorada/buscada visando atrair novas empresas, emprego e renda para a região com o desenvolvimento do pré-sal. 
Entendemos que o debate sobre o petróleo no estado do Rio de Janeiro ocorre muitas vezes de forma desfocada. O problema no estado é ter o complexo de petróleo e gás ou é ter apenas a extração de petróleo em alto-mar, os royalties, sedes administrativas de empresas vinculadas ao complexo e parte da indústria naval? Ou seja, talvez estejamos, no estado do Rio de Janeiro, em situação mais próxima da Venezuela, que extrai e vende petróleo bruto, do que a de regiões como a Noruega, em que o complexo do petróelo e gás é adequadamente aproveitado, sendo responsável por um em cada nove empregos existentes naquele país.

É claro que parte das demandas do pré-sal será atendida pela indústria já instalada em São Paulo. No entanto, conforme pesquisas que realizamos quando da organização do Plano Diretor do Arco Metropolitano ${ }^{27}$, a exploração do pré-sal e sua nova escala permitirão a presença, no Brasil, de novas atividades produtivas para atender as demandas desse complexo. Podemos, então, desenhar uma política que permita identificar as novas oportunidades e atraí-las para o Rio de Janeiro, preferencialmente para a periferia metropolitana, quando se tratar de atividades industriais.

A crise política e econômica que se instaurou no Brasil em 2015 teve como um de seus eixos centrais a Petrobras e o conjunto do complexo, impactados pela queda do preço internacional do petróleo e também pelas investigações de corrupção do Ministério Público e da Polícia Federal. O Rio de Janeiro vem apresentando um desempenho, na crise, pior do que o Brasil, no que diz respeito à questão fiscal, principalmente pela forte queda das receitas de royalties. No entanto, no que tange ao conjunto dos indicadores econômicos, como, por exemplo, evolução do comércio, da indústria e do emprego, não se verifica, em 2015, uma situação do estado do Rio de Janeiro pior do que a do Brasil. Isso não será uma pista de que parte importante do complexo do petróleo e gás não se encontra no território fluminense?

Outro bloco econômico importante no território fluminense, que ainda pode ser muito potencializado e que apresenta sinergia entre suas atividades, é o vinculado às atividades de turismo, entretenimento, cultura, multimídia, esporte e lazer ${ }^{28}$.

A cidade e o estado do Rio de Janeiro têm clara potencialidade para o turismo, por suas belezas de mar e montanha; pela presença no estado de três entre os quatro parques nacionais mais importantes do país - Parque da Tijuca; Serra dos Órgãos; e Itatiaia -, pela importância histórica de regiões como a cidade do Rio; a Região do Médio Paraíba, com suas fazendas de café e a cidade imperial de Petrópolis; e pela potencialidade do que podemos denominar de turismo de convivência - aquele que se faz para conhecer a cultura, o estilo de vida e as especificidades de uma região.

A carência de planejamento no estado do Rio torna o turismo ainda muito pouco aproveitado. $\mathrm{Na}$ cidade do Rio, o total de empregos em hotéis e pousadas representa apenas em torno de $1 \%$ do total de empregos formais da cidade (MTE/Rais, 2014) ${ }^{29}$. Além disso, pesquisas por nós realizadas apontam que a atividade turística nas demais 91 cidades fluminenses só apresenta de fato significação para a economia municipal em Armação dos Búzios, Parati e Itatiaia.

A história do Rio também faz com que exista presença importante de atividades culturais e da área de cinema e vídeo na região. Além disso, a área de cinema e vídeo tem apresentado

\footnotetext{
$27 \quad$ Osorio et al., 2011.

28 Uma análise detalhada sobre esse complexo econômico, suas potencialidades e proposições de políticas pode ser vista em Osorio; Sobral, 2013.

29 O dado do total de empregos em hotéis e pousadas na cidade do Rio de Janeiro, em 2014, já incorpora boa parcela dos novos hotéis abertos em função dos megaeventos que ocorrem na cidade desde o Panamericano de 2007.
} 
forte crescimento, pela política de conteúdo nacional e fomento ao setor implantada pelo governo federal no início do século XXI, com aprovação de legislação específica à criação da Ancine e de um fundo vinculado a ela.

Já no que diz respeito às atividades de entretenimento, esporte e lazer, deve-se buscar adequado aproveitamento dos complexos esportivos criados ou aprimorados no Rio de Janeiro, tendo em vista os megaeventos. Nesse aspecto, uma possibilidade é buscar uma política que transforme a cidade do Rio na Capital do Esporte da América Latina. Outra posibilidade deriva do fato de que hoje em dia complexos esportivos não servem apenas como palco para competições, atendendo também outras atividades de entretenimento e lazer. Deve-se ter em conta ainda que a cidade do Rio de Janeiro, além de receber bem seus visitantes, já tem importante experiência em organização de megaeventos, desde a Eco 92, o que, com a realização das Olimpíadas de 2016, poderá permitir a geração de imagem internacional positiva para a cidade e contribuir para a alavancagem do turismo ${ }^{30}$.

Outra área em que pode ser definida uma política de adensamento produtivo no estado do Rio de Janeiro, vincula-se ao que podemos denominar de complexo da economia da saúde. O Sistema Único de Saúde brasileiro é o maior comprador público, entre todos os países do mundo, de insumos para uso no atendimento à área de saúde. Assim, a partir de 2004, o governo federal iniciou o desenho de uma política de criação ou atração para o país de novas atividades produtivas desse setor, com base no poder de compra do governo.

O Rio de Janeiro é espaço privilegiado para atrair essas novas atividades. O estado abriga uma significativa indústria farmacêutica; há importante área de pesquisa nesse setor, na região; e tem o privilégio de sediar a Fiocruz, instituição-chave nessa nova política, inclusive do ponto de vista de absorção de novas tecnologias ${ }^{31}$. Tem também presença importante na área de cirurgia plástica, atraindo moradores de outras regiões brasileiras e do exterior. Registre-se que a vinda de pessoas do exterior para aproveitar a expertise em cirurgia plástica do Rio de Janeiro pode ampliar-se, caso o fim da sobrevalorização cambial ocorrida a partir de 2016 venha a ser mantido.

Por último, é importante aprofundar os benefícios econômicos que podem advir da presença das Forças Armadas no Rio de Janeiro, não só pelos recursos que essa instituição injeta na economia, por meio de pagamentos de salários e das compras de insumos que realiza para a manutenção de suas ativiades, mas, também, pelas atividades de ensino, pesquisa e produção que empreende em nosso território, como, por exemplo, com o estaleiro nuclear da Marinha, que está sendo instalado no município de Itaguaí.

No que diz respeito ainda ao adensamento produtivo no estado do Rio de Janeiro, é importante desenhar uma estratégia de fomento territorializada, visando aumentar a endogenia da economia fluminense. Nessa estratégia, deve-se pensar a cidade do Rio de Janeiro como espaço de coordenação da economia regional. Entre as oito Regiões de Governo, os desafios mais complexos estão na Região Metropolitana do Rio de Janeiro e em sua periferia. Não só pelo fato de a RMRJ concentrar $74,3 \%$ da população fluminense; $77,4 \%$ dos empregos formais do estado; e $64,7 \%$ do PIB do estado, mas, também, por ser a região, no território fluminense, com maiores desafios do ponto de vista socioeconômico e da desigualdade social (IBGE e MTE).

\footnotetext{
30 Do ponto de vista do custo e dos investimentos gerados pela realização das Olimpíadas, diversos questionamentos podem ser feitos. Em primeiro lugar, começa a haver crescente entendimento de que a forma como se organizam as Olimpíadas deve ser simplificada. Em segundo lugar, a realização do evento em região de expansão territorial da cidade do Rio de Janeiro, na Zona Oeste, ao contrário do que ocorreu em Londres e Barcelona - em geral apresentadas como exemplos bem sucedidos do ponto de vista urbano -, pode gerar uma série de efeitos negativos, como a ampliação dos custos em infraestrutura, pela expansão territorial da cidade, e um maior distanciamento entre trabalho e moradia, o que é o oposto do que os urbanistas hoje em dia hegemonicamente indicam. Maior detalhamento dessa discussão, no entanto, não cabe no escopo deste artigo.
} 
Em primeiro lugar, a periferia metropolitana ainda é basicamente dormitório, o que gera diversos problemas, como, por exemplo, a existência, na quase totalidade de seus municípios, de uma diminuta base produtiva para arrecadação de receita pública municipal. Por exemplo, enquanto o município de São Caetano do Sul da periferia da RMSP, que apresenta forte densidade produtiva, possuía, em 2014, uma receita pública per capita de $\mathrm{R} \$ 6.832,86$, o município de Duque de Caxias (RMRJ), muitas vezes percebido no imaginário popular como um município rico, apresentava uma receita pública per capita de apenas $\mathrm{R} \$ 2.012,51^{32}$. Isto porque, apesar de a refinaria Duque de Caxias e outras poucas grandes empresas estarem em seu território, o conjunto de sua estrutura produtiva é extremamente rala (Finbra/STN/MF).

Da mesma forma, ao analisarmos os indicadores sociais na RMRJ e principalmente em sua periferia, vemos resultados bastante preocupantes, seja em uma comparação com os municípios fluminenses das outras sete Regiões do Governo; seja em uma comparação com o total dos municípios da Região Sudeste brasileira; seja ainda em rankings dos municípios com mais de cinquenta mil habitantes das periferias das RMRJ, RMSP e RMBH.

Entre os exemplos, para um ranking dos resultados na educação através do Índice de Oportunidades da Educação Brasileira-loeb, em 2013, verificamos que todos os piores resultados são dos dezoito municípios da periferia da RMRJ que possuem mais de 50 mil habitantes.

No quesito segurança, novamente comparando os municípios das periferias das RMRJ, RMSP e RMBH, com cinquenta mil habitantes ou mais, vemos que os municípios com os dois melhores resultados são São Caetano do Sul e São Bernardo, ambos da RMSP, que possuíam, em 2013, taxas de homicídios por cem mil habitantes de, respectivamente, 4,48 e 6,20. Por outro lado, vários municípios da RMRJ apresentavam elevadas taxas de homicídios, superiores a 40 por cem mil habitantes: Japeri, 41,67; Itaguaí, 51,06; Belford Roxo, 54,23; Duque de Caxias, 60,30; e Nova Iguaçu, 63,62 (Datasus).

A precarização da periferia metropolitana também pode ser vista ao realizarmos um ranking, para os 59 municípios com mais de cinquenta mil habitantes das periferias das metrópoles do Rio de Janeiro, SP e BH, do percentual de domicílios atendidos por rede de água, em 2010, observa-se que, entre os 18 piores resultados, estão 14 municípios da periferia da RMRJ. Aliado a isso, pelas informações que possuímos, a qualidade e periodicidade da chegada da água aos domicílios não são boas (Censo do IBGE, 2010).

Uma estratégia e uma agenda que permita o início de um círculo virtuoso para a RMRJ e principalmente sua periferia, deve pensar, de forma integrada, políticas sociais, de infraestrutura e de atração de investimentos. Essa estratégia e agenda deve levar em conta a questão da melhoria da educação e da formação profissional; da política pública de saúde; a criação de recursos de amenidades, como parques públicos, hoje inexistentes na periferia metropolitana, excetuando-se Niterói; a organização de zoneamento urbano e a regularização de terrenos para instalação de empresas; e melhoria da logística e da infraestrutura de telecomunicações, energia elétrica e saneamento. Isto, tanto para os cidadãos quanto para as empresas.

Um primeiro exemplo da necessidade de se pensar de forma integrada a questão da qualidade de vida na RMRJ e em sua periferia metropolitana evidencia-se em depoimentos de gestores públicos sobre o fato de que empresários que visitam o Rio de Janeiro avaliando a possibilidade de instalar atividades produtivas no estado, ficam impressionados com a falta de cidades organizadas na periferia metropolitana, onde seus funcionários possam trabalhar e viver bem. 
Outro exemplo é depoimento que recebemos de um empresário que produz materiais de construção e tem três plantas industriais, duas em São Paulo e uma na Baixada Fluminense. Ele afirmou que, apesar do Arco Metropolitano ter trazido melhoria logística, ele pensa em transferir a planta que possui na Baixada para São Paulo, tendo em vista que, muito frequentemente, cai a energia na região e não só a produção fica paralisada como ele perde o que estava em produção. Além disso, quando chove, ele perde sinal de internet e não pode sequer emitir nota fiscal eletrônica.

Último exemplo paradigmático das dificuldades para que ocorram atração de empresas, encadeamentos e adensamento produtivo na RMRJ, excluindo-se a cidade do Rio de Janeiro e Niterói, é o fato de que a instalação da Rio Polímeros em Campos Elíseos, no município de Duque de Caxias, não atraiu praticamente nenhuma nova indústria de plástico. Devese lembrar que a criação da Rio Polímeros, planta petroquímica de primeira e segunda geração, foi desenhada visando ser âncora de um pólo de gás químico que incorporaria também a terceira geração petroquímica, ou seja, a indústria de plásticos. A terceira geração petroquímica é fundamental pois não só é intensiva em mão de obra como, também é composta hegemonicamente de pequenas e médias empresas. A não atração de indústrias de plástico para a periferia metropolitana deveu-se fundamentalmente a não existência de áreas com infraestrutura adequada para sua instalação.

Se a RMRJ é a Região de Governo do estado do Rio de Janeiro com os maiores desafios do ponto de vista das políticas sociais, de infraestrutura e do adensamento produtivo, as outras sete Regiões de Governo estão longe de apresentar um quadro confortável, quando comparamos sua situação socioeconômica com a da grande maioria dos municípios das Regiões Sudeste e Sul brasileiras, como já apresentado neste artigo.

Nesse sentido, ampliar a reflexão sobre o estado do Rio de Janeiro e suas especificidades territoriais, de forma sistemática, é decisivo para o devido conhecimento e a socialização das informações sobre a realidade atual fluminense e para o debate social sobre qual é a agenda que possibilitará a superação das precariedades estruturais e da crise atual e o início de um círculo virtuoso no conjunto do estado. 


\section{Referências bibliográficas}

BARROS, Frederico Robalinho de. Economia Industrial do Novo Estado do Rio de Janeiro. Rio de Janeiro: APEC; IDEG, 1975.

BERNARDES, Lysia Maria Cavalcanti (Coord.). O Rio de Janeiro e sua região. Rio de Janeiro: IBGE/Conselho Nacional de Geografia, 1964.

DINIZ, Eli. Voto e Máquina Política Patronagem e Clientelismo no Rio de Janeiro. Rio de Janeiro: Paz e Terra, 1982.

DULCl, Otávio Soares. Política e recuperação econômica em Minas Gerais. Belo Horizonte: Ed. da UFMG, 1999.

. (Coord.). Crônica política do Rio de Janeiro. Rio de Janeiro: Ed. da FGV, 1998.

Em busca da Idade de Ouro: as elites políticas fluminenses na primeira República (1889-1930). Niterói: UFF. Instituto de Ciências Humanas e Filosofia, 1991.

FIANI, Ronaldo. Estado e economia no institucionalismo de Douglass North. Revista de Economia Política, v. 23, n. 2, abr./jun. 2003.

FREIRE, Américo. Uma capital para a República: poder federal e forças políticas locais no Rio de Janeiro na virada para o século XX. Rio de Janeiro: Revan, 2000.

GUANABARA. Secretaria de Ciência e Tecnologia. Comissão do ano 2000. Rio Ano 2000. Rio de Janeiro, 1970.

HASENCLEVER, Lia; PARANHOS, Julia. Complexo da economia da saúde no estado do Rio de Janeiro: uma oportunidade de ampliar o desenvolvimento do estado? In: OSORIO, Mauro et al. (Orgs.). Uma agenda para o Rio de Janeiro: estratégias públicas para o desenvolvimento socioeconômico. Rio de Janeiro: FGV Editora, 2015.

HIRSCHMAN, Alberto. Estratégia do desenvolvimento econômico. Rio de Janeiro: Fundo de Cultura, 1958.

HODGSON, Geoffrey M. Economia e evolução: o regresso da vida à teoria econômica. Oeiras: Celta, 1997.

IDEG-INSTITUTO DE DESENVOLVIMENTO DA GUANABARA. Tendências de crescimento da Guanabara. Rio de Janeiro: SENAI, 1974.

KRUGMAN, Paul; FUJITA, Masahisa; VENABLES, Anthony J. Economia espacial: urbanização, prosperidade econômica e desenvolvimento humano no mundo. São Paulo: Futura, 2002.

LESSA, Carlos. O Rio de todos os Brasis: uma reflexão em busca de auto-estima. Rio de Janeiro: Record, 2000.

MAGALHÃES, J. P. A. et al. Rio Século XXI: perspectivas e propostas para a economia fluminense. Rio de Janeiro: JB, 1991.

MAGALHÃES, Raphael de Almeida. Breve Histórico sobre a Estruturação Física e Econômica da Cidade e sua Região. [S.I.: S.n.], 2001. Texto mimeografado.

MELLO, João Manuel Cardoso de. O capitalismo tardio. São Paulo: Brasiliense, 1982. Saudades da Guanabara. Rio de Janeiro: Ed. da FGV, 2000.

MOTTA, Marly Silva da. Rio de Janeiro: de cidade-capital a Estado da Guanabara. Rio de Janeiro: ALERJ, 2001.

MOULAERT, Frank. Globalization and integrated area development in European cities. Nova lorque: Oxford University Press, 2000. 
MYRDALL, Gunnar. Teoria econômica e regiões subdesenvolvidas. 2. ed. Rio de Janeiro: Saga, 1968.

NORTH, Douglass C. Instituciones, cambio institucional y desempeño económico. México: Fondo de Cultura Económica, 1993.

OSORIO, Mauro. Rio nacional, Rio local: origens e especificidades da crise carioca e fluminense. Estratégias, Instituições e Desenvolvimento. Tese de Doutordado. Rio de Janeiro: Universidade Federal do Rio de Janeiro/Instituto de Planejamento Urbano e Regional da Universidade Federal do Rio de Janeiro, 2004.

Rio nacional, Rio local: mitos e visões da crise carioca e fluminense. Rio de Janeiro: SENAC, 2005.

et al. Análise da dinâmica espacial dos complexos logísticos-produtivos e recomendações para o maior impacto positivo dos empreendimentos estruturantes. Plano Diretor Estratégico de Desenvolvimento Sustentável da Meso-Região do Arco Metropolitano do Rio de Janeiro (Relatório Final da Política de Desenvolvimento Econômico e Social - PDES). Rio de Janeiro: Governo do Estado do Rio de Janeiro, 2011.

; SOBRAL, Bruno. A capacidade indutora dos serviços no estado do Rio de Janeiro. Relatório de pesquisa. Sebrae/RJ, agosto 2013.

; VERSIANI, Maria Helena. O papel das instituições na trajetória econômico-social do Estado do Rio de janeiro. Cadernos do Desenvolvimento Fluminense, n. 2, p. 1-23, 2013.

et al. (Orgs.). Uma agenda para o Rio de Janeiro: estratégias públicas para o desenvolvimento socioeconômico. Rio de Janeiro: FGV Editora, 2015.

; VERSIANI, Maria Helena; REIS, Paulo. A metrópole carioca. In: RODRIGUES, Theófilo (Org.). O Rio que queremos: propostas para uma cidade inclusiva. Rio de Janeiro: Editora NPC-Núcleo Piratininga de Comunicação, 2016, p. 82-94.

PACHECO, Carlos Américo. Fragmentação da nação. São Paulo: UNICAMP/IE, 1998.

RIBEIRO, Luiz Cesar de Queiroz (Org. e Coord.). Rio de Janeiro: transformações na ordem urbana. Rio de Janeiro: Letra Capital; Observatório das Metrópoles, 2015.

ROSA, Luiz Pinguelli (Coord.); OSORIO, Mauro (Subcoord.). O gás natural na América Latina, no Brasil e no Estado do Rio de Janeiro: algumas considerações. Cadernos de Energia n. 8; Rio de Janeiro: ENERGE/COPPE/UFRJ, JUNHO/1995.

SOBRAL, Bruno Leonardo Barth. Metrópole do Rio e projeto nacional: uma estratégia de desenvolvimento a partir de complexos e centralidades no território. Rio de Janeiro: Garamond, 2013.

SOBRAL, Bruno Leonardo Barth. A questão metropolitana em perspectiva: o desfio de tornar a periferia da RMRJ mais densa produtivamente e com melhor infraestrutura básica. In: OSORIO, Mauro et al. (Orgs.). Uma agenda para o Rio de Janeiro: estratégias públicas para o desenvolvimento socioeconômico. Rio de Janeiro: FGV Editora, 2015, p. $17-44$.

VEBLEN, Thorstein. The Theory of the Leisure Class. New York: Modern Library, 1934.

VERSIANI, Maria Helena. Padrões e práticas na política carioca: os deputados federais eleitos pela Guanabara em 1962 e 1970. Dissertação de Mestrado. Rio de Janeiro: Universidade Federal do Rio de Janeiro/Instituto de Filosofia e Ciências Socais/ Programa de Pós-Graduação em História Social, 2007. 